\title{
Acute pancreatitis associated with massive paraesophageal hernia involving the presence of the pancreatic body and tail
}

\author{
Bahjat Barakat, ${ }^{1}$ Lucia Calculli, ${ }^{2}$ Raffaele Pezzilli ${ }^{3}$ \\ ${ }^{1}$ Emergency Department; ${ }^{2}$ Department of Radiology; ${ }^{3}$ Department of Gastroenterology, Sant'Orsola- \\ Malpighi Hospital, Bologna, Italy
}

\begin{abstract}
Acute pancreatitis is an acute inflammation of the pancreas and, according to the 2013 Revised Atlanta Classification, the majority of cases have only a mild clinical course without organ dysfunction. The primary objectives in the treatment of acute pancreatitis are essentially relief of pain, electrolyte and fluid support and energy intake other than removal of the causal agent. Even if in Italy gallstones especially are the predominant etiological factor, there are also less frequent causes associated with acute pancreatitis and we believe that the case of acute pancreatitis associated with massive incarcerated paraesophageal hernia involving the presence of the body and tail of the pancreas in the thorax is worth reporting.
\end{abstract}

\section{Introduction}

Acute pancreatitis is an acute inflammation of the pancreas and, according to the Revised Atlanta Classification released in 2013 it is classified as mild (no presence of organ dysfunction), moderate (with transient less than $<48$ hours organ dysfunction) or severe (with persistent organ dysfunction). ${ }^{1}$ The primary objectives in the treatment of acute pancreatitis are essentially: pain control, electrolyte and fluids support, energy intake, and removal of the causal agent, attenuation of inflammation, and prevention and eventual treatment of local and systemic complications in necrotiz-

Correspondence: Raffaele Pezzilli, Department of Gastroenterology, Sant'Orsola-Malpighi Hospital, Via Massarenti 9, 40138 Bologna, Italy. E-mail: raffaele.pezzilli@aosp.bo.it

Key words: Acute pancreatitis; Type IV paraesophageal hernia; Computed tomography.

Contributions: the authors contributed equally.

Conflict of interest: the authors declare no potential conflict of interest.

Funding: none.

Received for publication: 12 June 2018.

Revision received: 30 October 2018.

Accepted for publication: 2 November 2018.

This work is licensed under a Creative Commons Attribution 4.0 License (by-nc 4.0).

(C) Copyright B. Barakat et al., 2018

Licensee PAGEPress, Italy

Emergency Care Journal 2018; 14:7617

doi:10.4081/ecj.2018.7617 ing forms. ${ }^{2}$ Gallstones are the predominant etiological factor especially in Italy followed by alcohol abuse. ${ }^{3}$ However, there also less frequent causes associated with acute pancreatitis and we believe that the case we describe is worth reporting.

\section{Case Report}

A 27-year-old male was admitted to our Emergency Room (ER) suffering from extensive abdominal pain which was dull and crampy in nature and associated with nausea and episodes of vomiting without blood. On the four days prior to admission, the pain with the same characteristics had been spasmodic but, after physical exertion in the swimming pool became continuous and intense with a value of eight on the visual analogue scale from $0-10 .{ }^{4} \mathrm{His}$ past medical history was unremarkable. In ER, blood pressure was normal (120$80 \mathrm{~mm} / \mathrm{Hg}$ ), temperature was $36^{\circ} \mathrm{C}$, heart rate $78 \mathrm{bpm}$, respiratory rate $18, \mathrm{O}_{2}$ saturation $90 \%$ in ambient air. On physical examination the abdomen was soft with mild epigastric tenderness and normal bowel sounds. Both cardiovascular and pulmonary examinations were normal. Blood tests revealed an increase of WCC $(23,340$ $\mathrm{mmc}$ ), amylase $677 \mathrm{U} / \mathrm{L}$ (upper reference limit $100 \mathrm{U} / \mathrm{L}$ ), lipase 1,602 U/L (upper reference limit $67 \mathrm{U} / \mathrm{L}$ ); liver and kidney functions were normal as were serum electrolytes and C-reactive protein level. Chest and abdominal $\mathrm{x}$-rays revealed the presence of a large hiatal hernia containing some intestinal loops in the thorax (Figure 1A); marked gastric dilation was also present (Figure 1B). Thorax and abdominal contrast enhanced computed tomography was performed confirming the hiatal hernia, the presence of the stomach with air fluid level, the first part of the duodenum, spleen, body and tail of the pancreas in the thorax (Figure 2); a peripancreatic fluid collection was also present. Laboratory and imaging examinations were highly compatible with acute pancreatitis. The APACHE II score was less than 8 and the pancreatitis was classified as clinically mild. ${ }^{5}$ The patient underwent medical treatment with fluids and analgesics for the first 48 hours and the pain progressively subsided; subsequently a surgical approach was carried out consisting of the reduction of viscera in the abdomen and the reconstruction of the diaphragm by direct plastic surgery. The patient's clinical course was uneventful (Figure 3) and one year after, he had no further attacks of pancreatitis.

\section{Discussion}

We have reported a rare case of a massive incarcerated paraesophageal hernia involving the presence of the stomach, the first part of the duodenum, the spleen and the body and tail of the pancreas in the thorax causing acute pancreatitis. The past medical history of the patient was unremarkable, thus it is impossible to say whether he had a congenital Bockdaleck or a hiatal hernia. 
Anyway, the pathogenesis resulted from the obstruction of the distal pancreatic duct after displacement of the pancreatic head and body into the thorax as part of a type IV paraesophageal hernia. ${ }^{6}$ The traction on the pancreas, due to acute distension and volvulus of the stomach, might have had also a role in the genesis of pancreatitis. ${ }^{7}$ Hiatal hernias are usually classified into the following types depending on the extent of herniation and the position of the gastroesophageal junction: type I, sliding hernias; type II, paraesophageal hernias; type III, mixed sliding and paraesophageal hernia (with elements of both types I and II) and type IV, herniation of
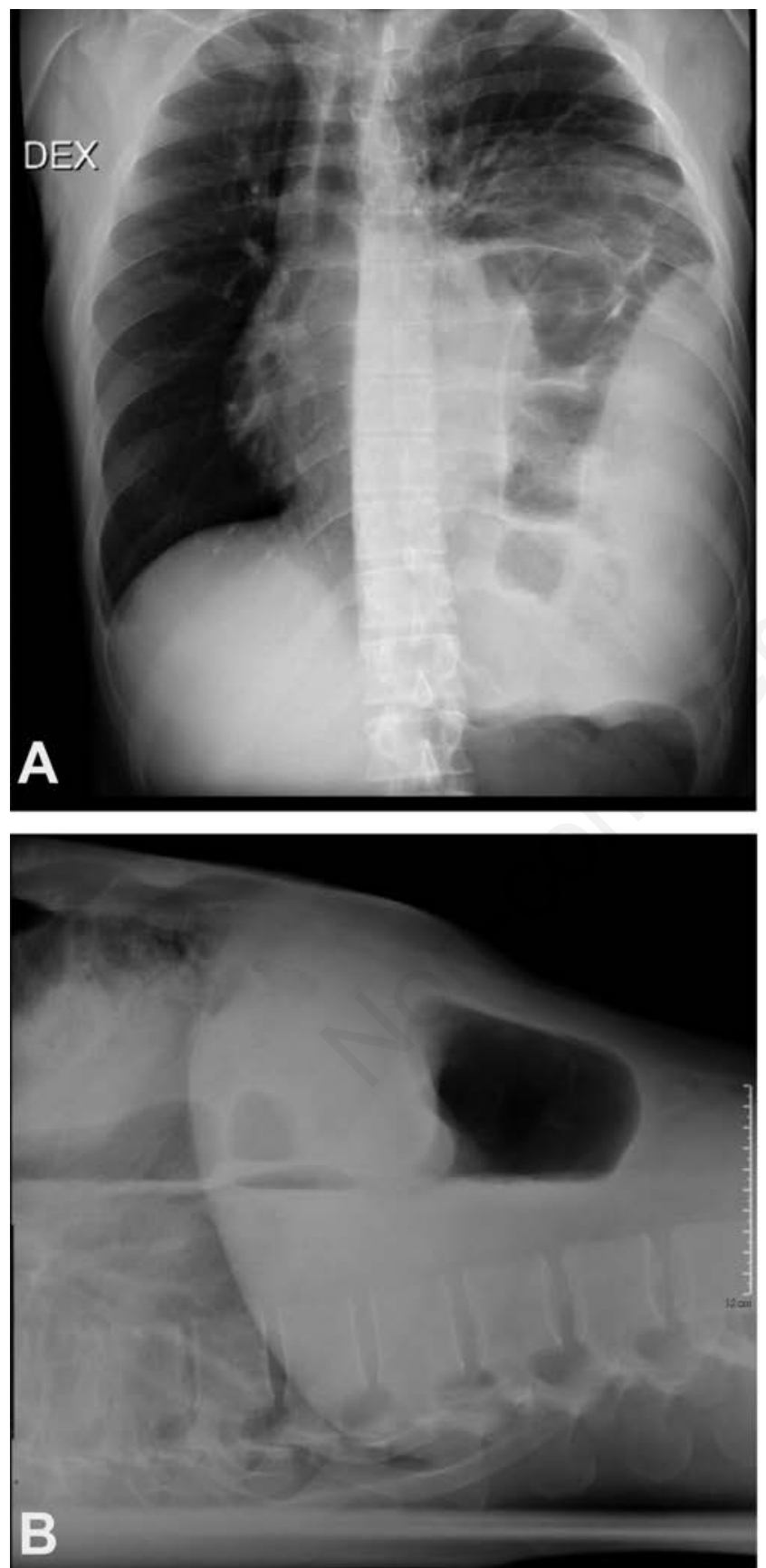

Figure 1. (A) Chest $x$-ray showing the presence of the bowel in the mediastinum; (B) Chest $x$-ray presence of gastric air bubble in the thorax.
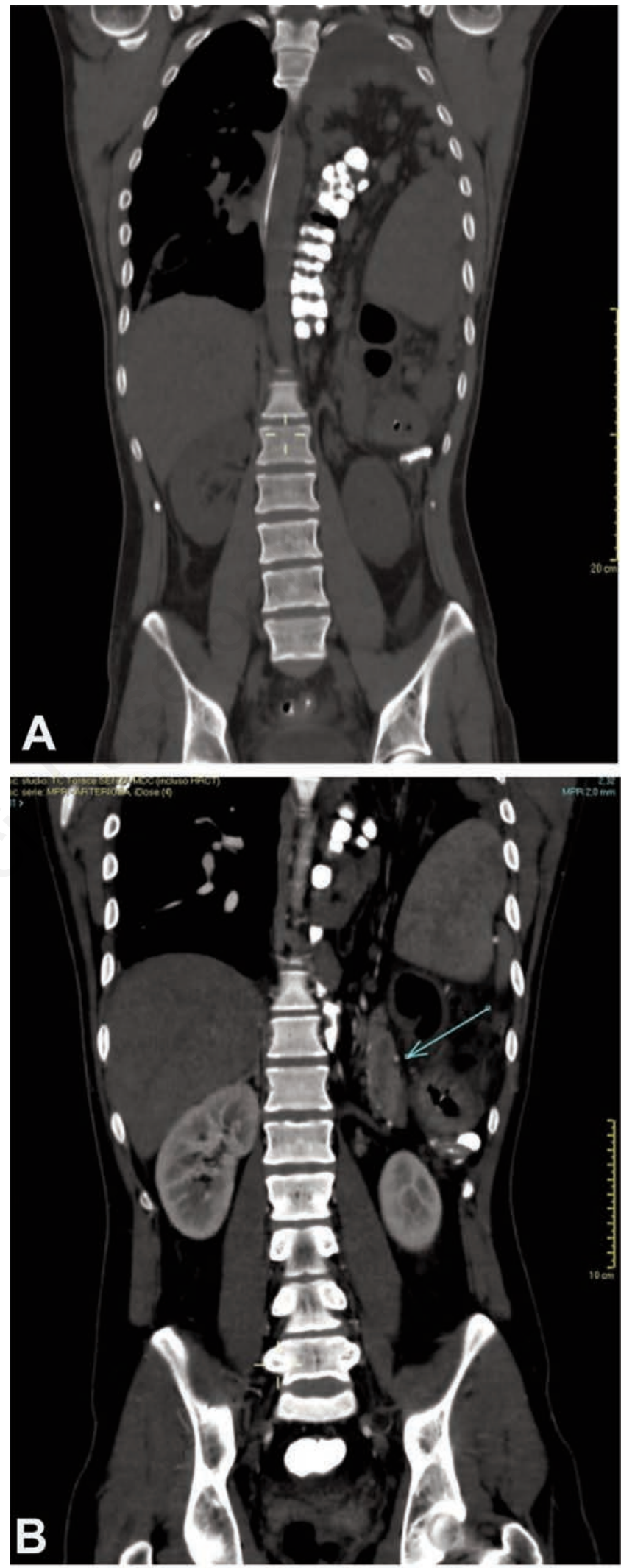

Figure 2. Contrast-enhanced computed tomography, coronal plane. (A) Hiatal hernia; (B) herniation of the stomach, the body and tail of the pancreas (arrow), and the first part of the duodenum. 
additional organs (such as colon, spleen, pancreas and small intestine, which enter the hernia sac) ${ }^{8,9}$ Type IV paraesophageal hernias account for $0.1 \%$ of all types of hiatal hernias ${ }^{10}$ and it is also known as giant hiatal hernia. Our patient initially underwent medical treatment according to the guidelines on acute pancreatitis. ${ }^{2}$ Subsequently, to remove the cause of further pancreatitis attacks we decided to operate in order to repair the hernia according to the guidelines which suggest that all symptomatic paraesophageal hiatal hernias should be repaired and this constitutes a strong evidence. ${ }^{6}$ Post-surgery imaging showed how successful the operation had been. Complications such as volvulus, occlusion, ischemia, or even perforation can, however, occur. ${ }^{8,11}$ Some cases of this rare cause of acute pancreatitis have been reported in literature in the past. ${ }^{12-24}$ Migration of pancreas in the thorax has been also reported not associated with acute pancreatitis ${ }^{25-29}$ or with symptoms of mechanical cholestasis such as mild jaundice, pruritus, diarrhea and fatigue..$^{30}$ In the majority of cases a herniated pancreas may be the body and the tail and in fewer cases the tail alone. Standard preoperative investigations include a CT scan of the chest/abdomen, ${ }^{12,18,20,22,23}$ magnetic resonance of the abdomen, ${ }^{24}$ an upper gastrointestinal contrast study and upper gastrointestinal endoscopy. ${ }^{31,32}$ Magnetic resonance may offer the opportunity to investigate the pancreatic and bile ducts in these rare cases. ${ }^{24}$ The

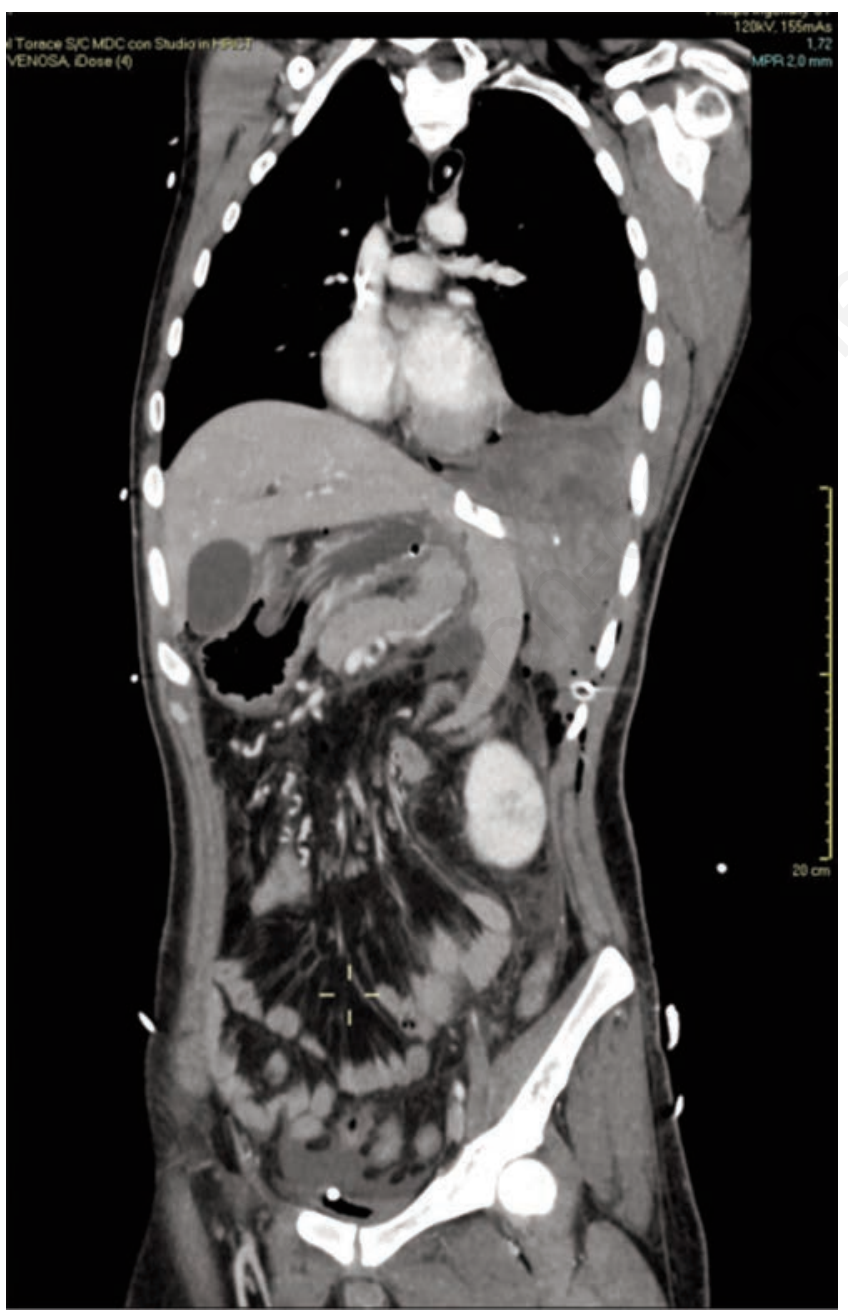

Figure 3. Contrast-enhanced computed tomography, coronal plane: imaging after surgical repair of the hernia.

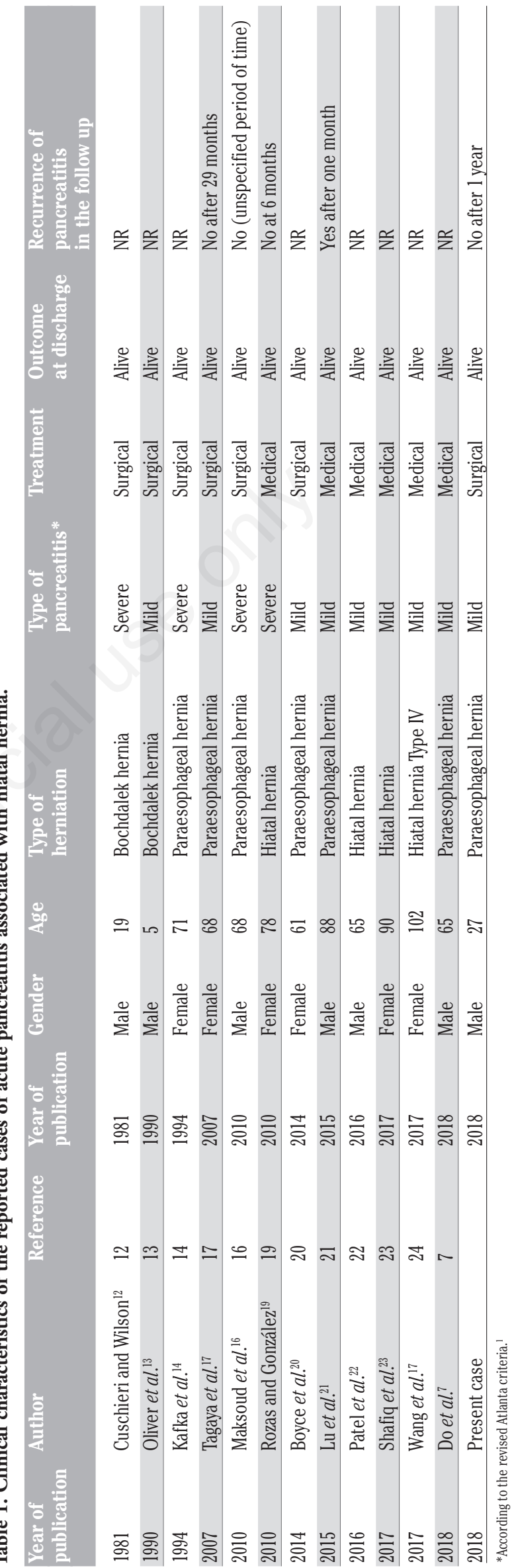


causes postulated for acute pancreatitis are repetitive trauma associated with pancreatic movement across the hernia, ischemic compromise of the vascular pedicle, and intermittent folding of the main pancreatic duct. ${ }^{12,13,18}$ The majority of patients have undergone surgery to repair their hernia and only a small number of patients have undergone conservative treatment as they have refused surgery. ${ }^{19,22-24}$

\section{Conclusions}

In conclusion, this is rare case of acute pancreatitis may be due to an incarcerated paraesophageal hernia involving the presence of the pancreas. As reported in Table 1, the association of acute pancreatitis and hiatal hernia is very rare; to our best knowledge only 13 cases have been reported in literature and their number increases over the years; there were mainly patients of advanced age and the clinical course of pancreatitis was usually mild, according to the revised Atlanta criteria. ${ }^{1}$ However, the causes of acute pancreatitis are not well-defined and may be due to repetitive trauma associated with pancreatic movement across the hernia, ischemic pancreatitis secondary to the vascular pedicle and intermittent folding of the main pancreatic duct. A conservative treatment is the preferred therapeutic approach in acute pancreatitis, but when the condition has a mechanical cause the possibility of emergency surgery should also be considered, in order to prevent both the consequences of a prolonged pulmonary collapse and further pancreatitis attacks.

\section{References}

1. Banks PA, Bollen TL, Dervenis C, et al. Acute pancreatitis classification working group. classification of acute pancreatitis-2012: revision of the Atlanta classification and definitions by international consensus. Gut 2013;62:102-11.

2. Pezzilli R, Zerbi A, Di Carlo V, Working Group of the Italian Association for the Study of the Pancreas on Acute Pancreatitis. Practical guidelines for acute pancreatitis. Pancreatology 2010;10:523-535.

3. Pezzilli R, Uomo G, Gabbrielli A, ProInf-AISP Study Group. A prospective multicenter survey on the treatment of acute pancreatitis in Italy. Dig Liver Dis 2007;39:838-46.

4. Scott J, Huskisson EC. Graphic representation of pain. Pain 1976;2:175-84

5. Pezzilli R, Zerbi A, Campra D, et al. Consensus guidelines on severe acute pancreatitis. Dig Liver Dis 2015;47:532-43.

6. Kohn GP, Price RR, Demeester S, SAGES Guidelines Committee. The Society of American Gastrointestinal and Endoscopic Surgeons (SAGES). Guidelines for the Management of Hiatal Hernias. Available from: http://www.sages.org/publications/guidelines/guidelines-forthe-management-of-hiatal-hernia/. Accessed: June 2, 2018.

7. Do D, Mudroch S, Chen P, et al. A rare case of pancreatitis from pancreatic herniation. J Med Cases 2018;9:154-6.

8. Mitiek MO, Andrade RS. Giant hiatal hernia. Ann Thorac Surg 2010;89:S2168-73.

9. Awais O, Luketich JD. Management of giant paraesophageal hernia. Minerva Chir 2009;64:159-68.

10. Maish MS, DeMeester SR. Paraesophageal hernia. In: Cameron JL, ed. Current surgical therapy. 8th ed. Philadelphia: Saunders; 2004. p 38.
11. Rade F, Lefevre JH. Giant hiatal hernia with biliopancreatic duct dilatation. Am Surg 2012;78:E534-5.

12. Cuschieri RJ, Wilson WA. Incarcerated Bochdalek hernia presenting as acute pancreatitis. Br J Surg 1981;68:668-9.

13. Oliver MJ, Wilson AR, Kapila L. Acute pancreatitis and gastric volvulus occurring in a congenital diaphragmatic hernia. J Paediatr Surg 1990;25:1240-1.

14. Kafka NJ, Leitman IM, Tromba J. Acute pancreatitis secondary to incarcerated paraesophageal hernia. Surgery $1994 ; 115$ : 653-5.

15. Saxena P, Konstantinov IE, Koniuszko MD, et al. Hiatal herniation of the pancreas: diagnosis and surgical management. J Thorac Cardiovasc Surg 2006;131:1204-5.

16. Maksoud C, Shah AM, DePasquale J, et al. Transient pancreatic hiatal herniation causing acute pancreatitis. A literature review. Hepatogastroenterology 2010;57:165-6.

17. Tagaya N, Tachibana M, Kijima H, et al. Laparoscopic treatment of paraesophageal hiatal hernia with incarceration of the pancreas and jejunum. Surg Laparosc Endosc Percutan Tech 2007; 17:313-6.

18. Chevallier P, Peten E, Pellegrino C, et al. Hiatal hernia with pancreatic volvulus: a rare cause of acute pancreatitis. AJR Am J Roentgenol 2001;177:373-4.

19. Rozas MG, González MM. A rare complication of hiatal hernia. Gastroenterology 2010;139:e1-e2.

20. Boyce K, Campbell W, Taylor M. Acute pancreatitis secondary to an incarcerated paraoesophageal hernia: a rare cause for a common problem. Clin Med Insights Case Rep 2014;11:25-7.

21. Lu LX, Payne M, Theobald CN. Education and imaging. Gastroenterology: Diaphragmatic herniation and pancreatitis. J Gastroenterol Hepatol 2015;30:653.

22. Patel S, Shahzad G, Jawairia M, et al. Hiatus hernia: a rare cause of acute pancreatitis. Case Rep Med 2016;2016:2531925.

23. Shafiq M, Badshah MB, Badshah MB, et al. Pancreas herniation into the mediastinum: a case report. BMC Res Notes 2017; $10: 450$.

24. Wang J, Thaker AM, Noor El-Nachef W, Watson RR. Transhiatal herniation of the pancreas: a rare cause of acute pancreatitis. ACG Case Rep J 2017;4:e66.

25. Coral A, Jones SN, Lees WR. Dorsal pancreas presenting as a mass in the chest. AJR Am J Roentgenol 1987;149:718-20.

26. Skinner DB, Belsey RH. Surgical management of esophageal reflux and hiatus hernia. Long-term results with 1,030 patients. J Thorac Cardiovasc Surg 1967;53:33-54.

27. Coughlin M, Fanous M, Velanovich V. Herniated pancreatic body within a paraesophageal hernia. World J Gastrointest Surg 2011;3:29-30.

28. Yildiz I. Asymptomatic pancreatic body herniation complicated with periauricular squamous cell carcinoma. Eur J Radiol Open 2018;5:64-6.

29. Banimostafavi ES, Tayebi M. Large hiatal hernia with pancreatic body herniation: Case-report. Ann Med Surg (Lond) 2018;28:20-2.

30. Jäger T, Neureiter D, Nawara C, et al. Intrathoracic major duodenal papilla with transhiatal herniation of the pancreas and duodenum: A case report and review of the literature. World J Gastrointest Surg 2013;5:202-6.

31. Bawahab M, Mitchell P, Church N, Debru E. Management of acute paraoesophageal hernia. Surg Endosc 2009;23:255-9.

32. Khanna A, Finch G. Paraoesophageal herniation: a review. Surgeon 2011;9:104-11. 